superficial wound still remains unhealed. He leaves by this evening's train en route to England vic Bombay, haring obtained two years' furlough. He telegraphed from Bombay to say that he had borne the journey well, and was to embark in a troopship.

Madras.

\section{CASE OF ATTEMPTED PARACENTESIS PERICARDII.}

BY JOSEPH W. HUNT, M.D. LOND.,

HYSICIAN TO THE WOLVERHAMPTON AND STAFFORDSHIRE GENERAL FOSPITAL.

THE following case presents more than one point of interest, and shows the difficulty there sometimes is in diagnosing between a largely dilated heart and an adherent pericardium. Reported as shortly as possible, it is as follows:-

Henry W-, aged twenty-three, was sent into the hospital on Jan. 30th, 1880, under my care, by my friend Mr. Wells, towards the close of an attack of acute rheumatic fever. He had had a previous attack eleven years before, when his aortic valves had been affected. During the first week of his stay in the hospital his left pleura (which was filled with fluid) was twice aspirated for the relief of distressing palpitations, dyspnoea and orthopncea, and an attack of acute pleurisy on the right side was cut short by the application of leeches. When admitted he had a loud aortic diastolic murmur and a largely dilated heart, while in addition pericardial friction was audible over the greater portion of the cardiac area, and there were signs of much pericardial effusion. On Feb. 7th, as there were manifest signs of cardiac failure, and he was apparently on the brink of the grave, I determined to aspirate the pericardium. At that time the physical signs were noted as follows. Only slight pulsation over cardiac area; apex-beat weak and diffused about two inches and a half below nipple; intercostal spaces over lower portion of cardiac area obliterated; upper level of cardiac dulness indicated by a line drawn from the top of the sternum to the left nipple; cardiac sounds very weak below, but above midsternum loud and aceompanied by a marked systolic and diastolic bruit, not variable and not increased by pressure; only slight epigastric pulsation; jugulars not full; pulse very irregular, weak and compressible, varying from 60 to 70 or 80 per minute. Respiration 50 to 60 per minute. Marked orthopnoea. Thoroughly reoognising the fact that the heart was much dilated, and remarking to the pupils present on the possibility of pericardial adhesions complicating the case, I introduced the finest needle into the pericardium through the fourth interspace near the sternum, and pushed it steadily on for more than an inch, its point being directed upwards. As no fluid came, and the violent pulsation of the needle showed that it had entered the heart walls, it was withdrawn, a little blood being found within the point. No bad symptom followed, and it was my intention to repeat the attempt another day, entering the pericardium an interspace or two higher up, but was prevented by the temporary improvement of the patient, and by a considerable fall in the amount of pericardial dulness. He died from cardiac failure on February 14th. The medical treatment adopted consisted, for the most part, in the frequent administration of digitalis, carbonate of ammonia, and stimulants. Occasionally other remedies were prescribed as required.

At the post-mortem examination the heart was found to be enormously enlarged; it reached from the right border of the sternum to the left nipple, and extended to the top of the sternum. Its right border was crossed by the right lung which was emphysematous, and extended over the middle line. The pericardium was adherent throughout. Over the lower portion the adhesions were strong, and evidently dated some time back, but over the upper portion they were slender, and did not closely bind down the pericardinm to the heart, while in their meshes there was some a mount of fluid, which was evidently undergoing absorption. On removal, the heart, filled with clot, weighed $31 \mathrm{oz}$; when emptied of clot, $28 \mathrm{oz}$. The aortic valves were incompetent. The left ventricle was enormously dilated, and the muscalar walls very much thicker than normal ; from their paleness and softness they were evidently undergoing degenerative changes. The left auricle was also hypertrophied and dilated, but the right ventricle only to a slight extent. The mitral was thickened, and its chordæ tendineæ thickened and shortened, so that it probably failed to close completely the auriculo-ventricular orifice. The mark of the aspirator-needle could be distinctly seen in the adherent pericardium over the right rentricle, whence its course could be traced for over an inch through the wall of the right ventricle into the very much hypertrophied ventricular septum. It nowhere entered either ventricle. There was no trace of inflammation, or any other morbid changes along the track of the needle.

Remarks. - The diagnosis in this case was no doubt diffi cult. A large amount of cardiac dilatation and hypertrophy, depending on the old standing aortic disease, was evident, while the presence of pericardial adhesions to some extent was more than probable. On the other hand, the very large area of cardiac dulness, the obliteration of intercostal spaces, the amount of pericardial friction audible on admission, and which was afterwards lost, rendered the presence of a large amount of effusion probable; and no doubt a considerable amount of fluid, which was afterwards absorbed, would have been withdrawn if I had inserted the needle a little higher up, as $I$ fully intended to do if a second aspiration was indicated. It must be remembered that it was impossible to trace any increase of pericardial dulness at the commencement of his stay in the hospital, owing to the left chest being completely filled with pleural effusion, and pleural and pericardial dulness thus running into each other. The physical signs noted above are what were evident after the pleura had been emptied by two aspirations. It is worth remarking the absence of any ill effects following the introduction of the needle for some considerable distance into the heart walls, and I believe that no harm would have followed even if the needle had entered the ventricle, provided it had been immediately withdrawn, before the contraction of the cardiac walls had helped the needle to tear up their substance. This case may be compared with another in which I attempted to aspirate the pericardium in a case of pericardial effusion complicating rheumatic fever. To my surprise only a few drops of fluid were obtained. The patient died of hyperpyrexia, and post-mortem it was found that the pericardium was widely distended with fluid, but that at the one spot where I aspirated there were adhesions between the heart and pericardinm, among which the needle had got entangled and blocked. At all other parts the heart was free from adhesions.

Wolverhampton.

\section{ON GENERAL PARALYSIS OF THE INSANE} CONSECUTIVE TO LOCOMOTOR ATAXY.

By W. JULIUS MICKLE, M.D., M.R.C.P., MEDICAL SUPERINTENDENT, GROVE HALI ASYLUM, LONDON.

I HAVE elsewhere ${ }^{1}$ briefly referred to the subject of general paralysis consecutive to locomotor ataxy. ${ }^{2}$ The cases referred to are those in which the symptoms of true general paralysis of the insane follow on those of true locomotor ataxy, and in which the pathological lesions of general paralysis have been supposed to originate in an extension upwards from the lesions of progressive locomotor ataxia. These cases, and others of like pathological import, have been designated as examples of general paralysis by propagation. The cases just mentioned, as other than those beginning with locomotor ataxy, but of like pathological import, are cases in which some cranial nerve or nerves have first suffered disease, the extension of which to the brain has set up some pathological process ending in general paralysis.

Broadly speaking, in general paralysis the rule is that cerebral symptoms precede spinal. Spinal symptoms, indeed, may be absent or slight, and when present, as a rule, they are secondary both in time and in importance. The usual motor spinal symptoms are either ataxiform or

1 General Paralysis of the Insane, 1880, pp. 89, 83, 141 .

2 The disease, "progressive locomotor ataxy," is Jeferred to throughont this paper, not the mere symptom, the affection of gait. 